\title{
Simulasi Sistem Pengisian Bahan Bakar Otomatis untuk Generator Set pada Unit Excavator 313D
}

\author{
Mukhtar $^{1^{*} \text { dan Peri Pitriadi }}{ }^{2}$ \\ 1,2 Jurusan Teknik Mesin, Politeknik Negeri Ujung Pandang, Makassar 90245, Indonesia \\ *email: $\underline{\text { mukhtar@poliupg.ac.id }}$
}

\begin{abstract}
Excavator is one of the heavy equipment used in construction work which consists of an arm, stick, and bucket driven by hydraulic power. The D-3 Study Program in Heavy Equipment Maintenance Engineering has a Caterpillar $313 D$ excavator unit, which in its operation must always be suitable for use according to standards such as good maintenance and routine refueling. The process of refueling is still carried out the conventional way, namely by refueling by lifting jerry cans of diesel fuel to the top of the unit can be at risk of work accidents. Therefore, to minimize this, it is necessary to have an automatic filling system. In this research, the system will use automatic for refueling using an Arduino Uno type microcontroller as a control system and an ultrasonic as a sensor for reading the fuel level in the tank.
\end{abstract}

Keywords: Excavator 313D; Water Level Control; Arduino Uno, Ultrasonic Sensor.

\begin{abstract}
Abstrak: Excavator merupakan salah satu alat berat yang digunakan pada pekerjaan konstruksi yang terdiri dari sebuah arm, tongkat dan bucket yang digerakkan oleh tenaga hidrolis. Program studi D-3 Teknik Perawatan alat berat memiliki unit Excavator Caterpillar 313D, dimana dalam pengoperasiannya harus selalu layak pakai sesuai standar seperti perawatan yang baik dan pengisian bahan bakar yang rutin. Proses pengisian bahan bakar masih dilakukan dengan cara konvensional yaitu dengan mengisi bahan bakar dengan mengangkat jerigen solar ke atas unit yang dapat beresiko terjadinya kecelakaan kerja. Oleh karena itu, untuk meminimalisir hal tersebut perlu adanya sebuah sistem pengisian otomatis. Dalam penelitian ini akan dibuat sebuah sistem yang dapat digunakan untuk pengisian bahan bakar secara otomatis dengan menggunakan mikrokontroller jenis Arduino uno sebagai sistem pengontrolannya dan sensor ultrasonic sebagai sensor untuk membaca ketinggian bahan bakar dalam tangki.
\end{abstract}

Kata kunci: Excavator 313D, Water Level Control, Arduino Uno, sensor ultrasonic.

\section{PENDAHULUAN}

Excavator merupakan salah satu alat berat yang digunakan pada pekerjaan konstruksi untuk memindahkan material. Alat Berat ini terangkai dari sebuah batang atau lengan (arm), tongkat atau boom, bucket (alat keruk) dan digerakkan oleh tenaga hidrolis yang dimotori dengan mesin diesel yang berada di atas roda rantai (trackshoe)[1]. Program Studi D-3 Teknik Perawatan Alat Berat Jurusan Teknik Mesin Politeknik Negeri Ujung memiliki unit Excavator Caterpillar 313D. Excavator jenis ini termasuk ke dalam excavator kecil yang biasanya digunakan untuk keperluan seperti pembuatan parit, memuat material, mengangkat material, dan lain-lain. Dalam pengoperasian seharihari untuk jenis Excavator 313D ini kondisinya harus selalu layak pakai sesuai standar. Oleh karena itu, selain dibutuhkan perawatan yang baik excavator juga membutuhkan bahan bakar yang siap untuk diisikan ke dalam fuel tank. Selama ini proses pengisian bahan bakar yang dilakukan dengan cara konvensional, maksudnya proses pengisian bahan bakar masih dilakukan dengan mengangkar jerigen solar ke atas unit. Dalam proses pengisian harus meminimalisir resiko yang mungkin saja terjadi seperti kecelakaan kerja dan kontaminasi dengan material lain seperti debu yang dapat merusak sistem pada mesin ketika bercampur dengan bahan bakar di dalam tangki serta pengisian bahan bakar harus dihentikan sebelum meluap dan menyisakan ruang untuk ekspansi sehingga tidak boleh diisi secara berlebihan[2].

Untuk mencegah resiko terjadinya kecelakaan kerja selama pengisian bahan bakar, maka dalam penelitian ini akan membuat suatu sistem pengisian otomatis bahan bakar ke dalam tangki. Sistem 
pengisian bahan bakar ini menggunakan konsep dari water level control dimana dengan konsep ini sudah digunakan dalam beberapa penelitian seperti pada penelitian [3] yang memanfaatkan water level control untuk pengisian otomatis tandon air, dimana konsepnya sistem otomatis sederhana ini adalah ketika air didalam tandon mulai berkurang, maka botol plastik akan turun kebawah dan tali yang terhubung antara botol plastik dan saklar akan saling tertarik dan mengakibatkan pengait besi tertarik dan mengubah saklar yang terhubung pompa air dari kondisi off menjadi on. Penelitian lainnya [4] yang menggunakan mikrokontroller untuk membuat sistem water level control pada daerah embung kering, sistemnya menggunakan mikrokontroller dan sensor. Sistem water level control yang akan dibuat dalam penelitian ini yaitu menggunakan Arduino, dimana Arduino ini telah banyak dimanfaatkan untuk sistem-sistem pengontrolan otomatis[5][6]. Dalam water level control, ketinggian air menjadi hal yang paling penting sebagai input dari pengotrolan oleh sebab itu perlu adanya sebuah sensor yang dapat membaca level dari ketinggian air tersebut. Pada penelitian yang dilakukan oleh Azhari [7], dimana dalam penelitiannya menggunakan sensor infra merah dan dalam penelitian yang dilakukan oleh Adhitya, dkk[8] yakni menggunakan sensor ultrasonic untuk membaca ketinggian air. Sensor ultrasonic merupakan alat yang berfungsi untuk mengubah besaran bunyi menjadi besaran listrik dan sebaliknya, dimana sensor ini bekerja berdasarkan pantulan gelombang suara untuk menafsirkan jarak sesuatu objek dengan frekuensi tertentu[9].

\section{METODE PENELITIAN}

\section{A. Rancangan Penelitian}

Rancangan penelitian yang akan dilakukan seperti yang terlihat pada Gambar 1 dan Gambar 2, dimana dalam sistem terdiri dari tiga bagian utama yang memiliki fungsi dan kerja masing-masing. Input merupakan hasil-hasil pembacaan dari sensor yang akan diproses di bagian control dan output merupakan hasil pemrosesan data dari input.

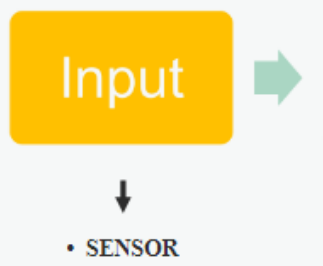

SENSOR

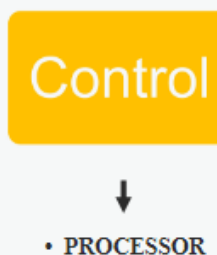

- PROCESSOR

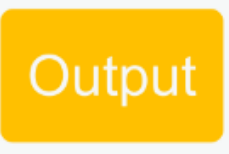

$\downarrow$

- RELAY

- BUZZER

- LCD

Gambar 1. Diagram sistem kontrol

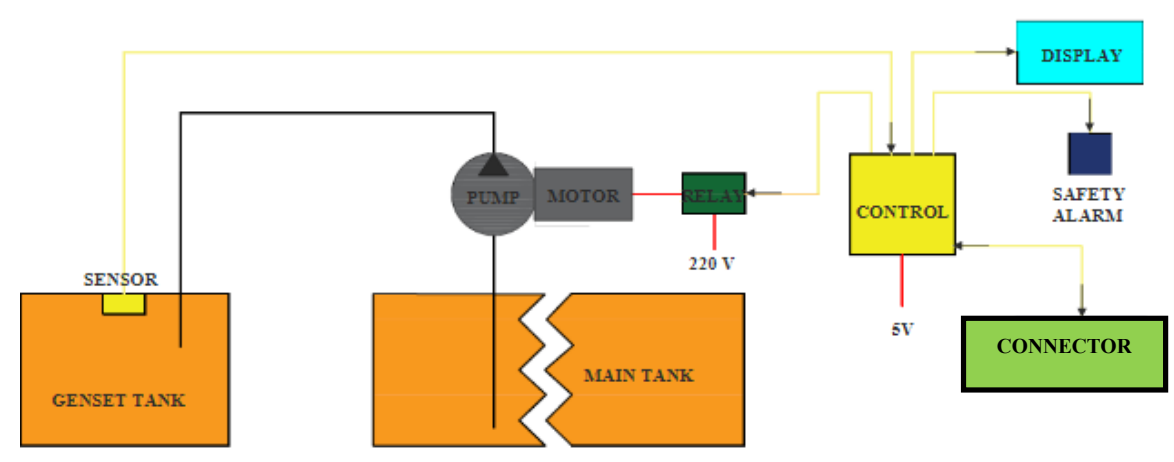

Gambar 2. Blok diagram sistem pengisian bahan bakar otomatis 
Berdasarkan blok diagram sistem pengisian otomatis ini menggunakan sensor yang berfungsi untuk mendeteksi tinggi bahan bakar dalam tangki generator set. Main tank merupakan tangki penyimpanan bahan bakar sementara yang nantinya didistribusikan ke tanki generator set. Sistem kontrol berfungsi untuk memonitor tinggi bahan bakar dan mengontrol distribusi bahan bakar secara otomatis. Alur kerja sistem pengisian bakar otomatis yang akan dilakukan dalam penelitian ini dapat dilihat pada flowchart Gambar 3.

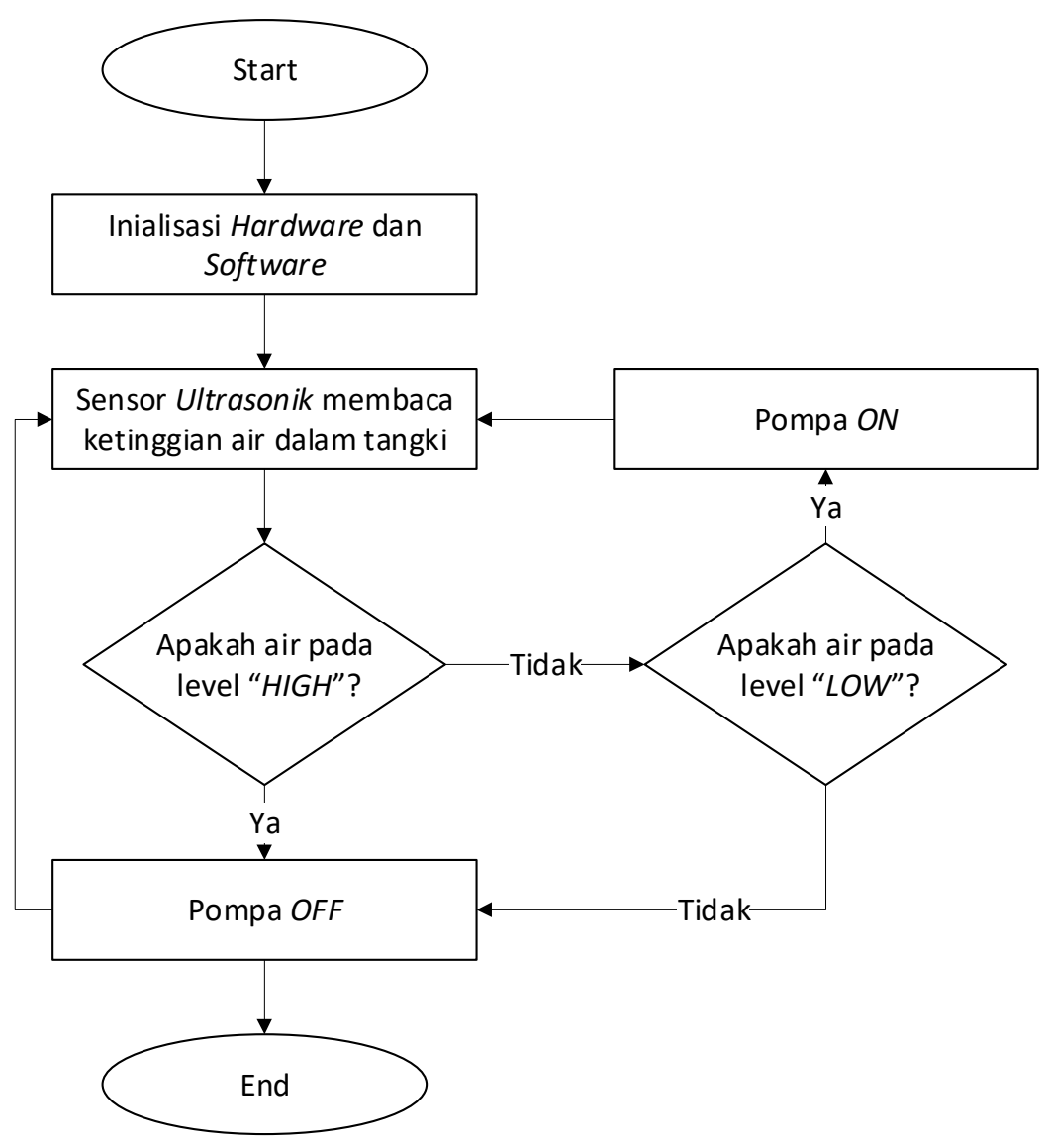

Gambar 3. Flowchart sistem pengisian bahan bakar otomatis

\section{B. Rancangan sistem}

Rancangan sistem pengisian bahan bakar otomatis akan dilakukan yaitu, menggunakan pompa yang dikontrol oleh sebuah mikrokontroller untuk mengatur jumlah bahan bakar yang ada didalam tangki bahan bakar generator set seperti yang terlihat pada Gambar 4. 


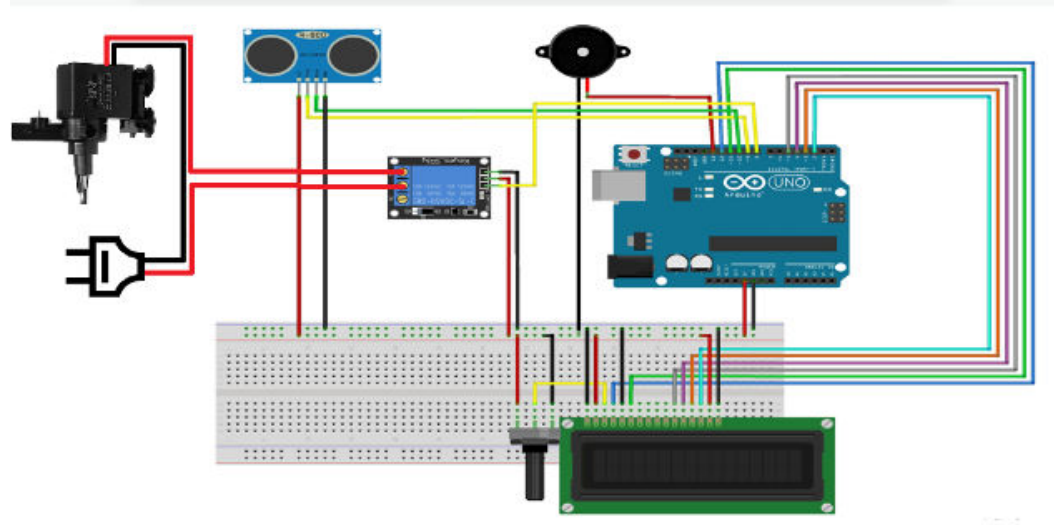

Gambar 4. Rangkaian sistem pengisian bahan bakar otomatis

Sistem pengisian otomatis menggunakan sebuah mikrokontroller Arduino yang berfungsi untuk mengontrol sensor-sensor yang ada pada bagian input dan output sistem. Pada bagian input terdapat sebuah sensor ultrasonik yang bekerja untuk memberikan data ketinggian bahan bakar yang ada di dalam tangki, data tersebut diproses oleh Arduino dan memberikan output berupa data ketinggian yang ditampilkan pada layar LCD. Pada bagian output juga terdapat sebuah relay yang aktif untuk menyalakan sebuah pompa pada ketinggian tertentu dan akan mematikan pompa apabila berada pada ketinggian tertentu pula sesuai dengan yang diprogramkan di Arduino. Selain relay bagian output juga terdapat sebuah sensor buzzer yang berfungsi sebagai alarm safety untuk sistem.

\section{HASIL DAN PEMBAHASAN}

Hasil perancangan sistem pengisian bahan bakar otomatis dapat dilihat pada Gambar 4 .

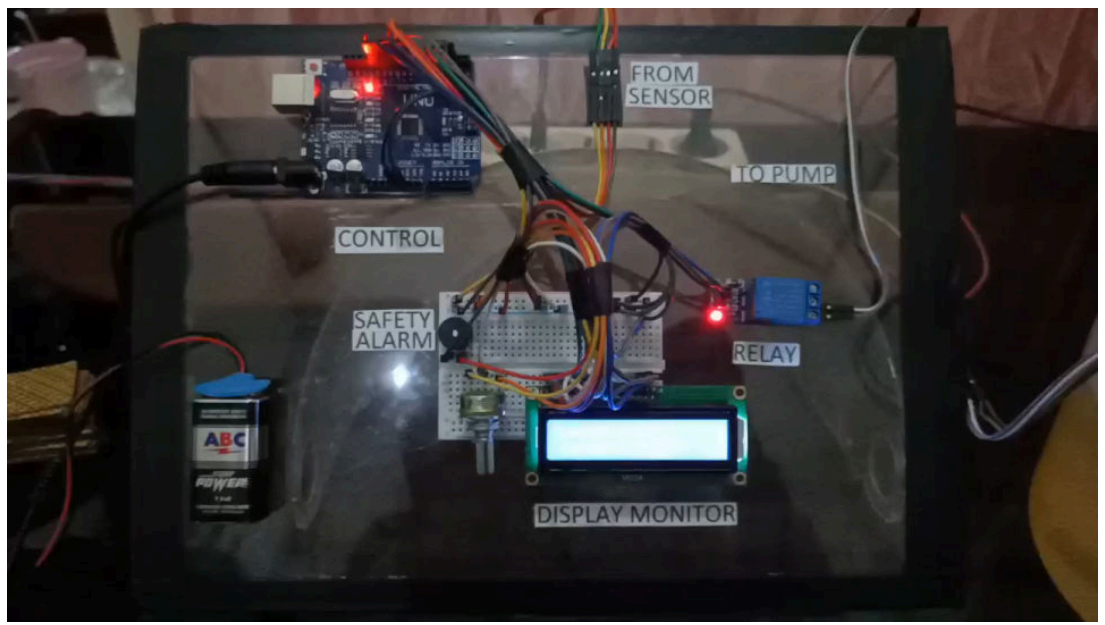

Gambar 4. Hasil perancangan sistem

Berdasarkan hasil dari perancangan yang telah dibuat, dalam penelitian ini menghasilkan sebuah alat sebagai prototipe pengisian bahan bakar secara otomatis yang secara umum menerapkan prinsipprinsip dari water level control. Water level control yang digunakan dalam penelitian ini seperti yang tampak pada Gambar 4, terdiri dari sensor ultrasonic sebagai input untuk membaca jarak, mikrokontroller sebagai alat control otomatis, relay sebagai saklar otomatis, LCD untuk menampilkan data jarak dan ketinggian air yang berasal dari sensor ultrasonic, pompa yang berfungsi untuk memompa bahan bakar dari main tank ke genset tank, baterai sebagai sumber daya sistem dan buzzer sebagai alarm ketika terjadi kesalahan prosedur dalam sistem. 
Proses pengisian otomatis dari sistem ini berdasarkan hasil pembacaan dari sensor ultrasonik yang membaca level permukaan dari bahan bakar dalam tangki generator set. Sensor ultrasonic dalam sistem ini merupakan komponen penting, karenakarena data hasil pembacaan jarak akan diolah untuk dibandingkan dengan data level minimum serta level maksimum ketinggian air. Kesalahan pembacaan data sensor jarak akan berdampak pada kesalahan pengambilan keputusan pada controller[8]. Prinsip kerja dari sensor ini yaitu mengubah besaran bunyi menjadi besaran listrik dan sebaliknya, dimana sensor ini bekerja berdasarkan pantulan gelombang suara untuk menafsirkan jarak sesuatu objek dengan frekuensi tertentu[9].

Jika bahan bakar yang yang digunakan sampai pada posisi level low sesuai yang telah diprogramkan dalam bagian controller, maka sensor ultrasonic akan membaca level tersebut dan mengirimkan data ketinggian ke bagian controller. Data dari sensor ultrasonic kemudian diproses di mikrokontroller untuk mengaktifkan relay yang telah diberi beban berupa pompa yang ditempatkan bagian main tank. Saat relay dalam keadaan aktif pompa akan bekerja untuk mengisi bahan bakar dari main tank ke genset tank secara otomatis.

Selama relay dalam keadaan aktif, pompa akan terus bekerja untuk melakukan pengisian bahan bakar ke dalam tangki sampai bahan bakar mencapai level high sesuai dengan pengaturan yang diprogramkan pada mikrokontroller. Pada level high ini sensor ultrasonic akan membaca level tersebut dan mengirimkan data ketinggian ke mikrokontroller dan selanjutnya memberikan perintah untuk menonaktifkan relay sehingga pompa akan berhenti bekerja dan proses pengisian dari main tank ke genset tank juga berhenti, proses ini akan berlangsung secara terus menerus dalam sistem. Dalam perancangan sistem ini dilengkapi display monitor untuk memantau kondisi ketinggian bahan bakar secara visual dan safety alarm untuk warning sistem apabila terjadi kesalahan dalam sistem.

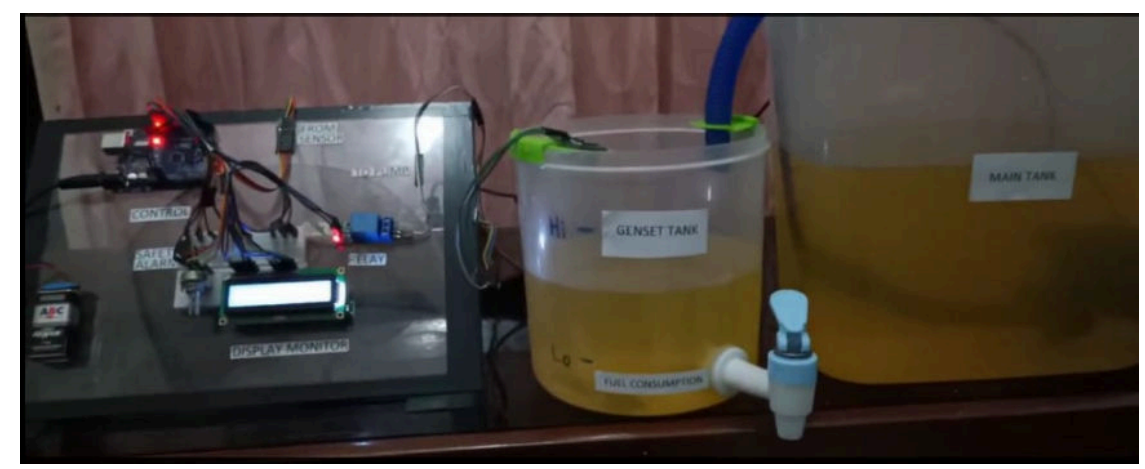

Gambar 5. Proses kerja pengisian bahan bakar

Hasil pengujian sistem pengisian bahan bakar otomatis dengan prinsip water level control dapat di lihat pada Tabel 1.

Tabel 1. Hasil Pengujian Pengisian Tangki

\begin{tabular}{|l|l|l|}
\hline Level & Jarak ketinggian bahan bakar dari sensor & Status pompa air \\
\hline$L O W$ & $10 \mathrm{~cm}$ & $O N$ \\
\hline$L O W<H I G H$ & $10 \mathrm{~cm} \geq 2 \mathrm{~cm}$ & $O N$ \\
\hline$H I G H$ & $2 \mathrm{~cm}$ & $O F F$ \\
\hline
\end{tabular}

Berdasarkan tabel hasil pengujian pada Tabel 1, diketahui bahwa proses pengisian bahan bakar terjadi ketika kondisi tangki dalam keadaan $L O W$. Selama proses pengisian pompa akan terus mengisi sampai mencapai level $H I G H$, pada level ini keadaan pompa akan berubah menjadi off sehingga proses pengisian akan berhenti. Level bahan bakar diukur berdasarkan jarak ketinggian bahan bakar dari 
sensor, jarak antara sensor dan bahan bakar sebesar $2 \mathrm{~cm}$ untuk level $H I G H$ dan jarak antara sensor dan bahan bakar $10 \mathrm{~cm}$ untuk level $L O W$. Ukuran jarak antara sensor dan ketinggian disesuaikan dengan bejana atau tempat penampungan yang berfungsi sebagai genset tank seperti yang tampak pada Gambar 5.

Tabel 2. Hasil Pengosongan / Penggunaan Bahan Bakar

\begin{tabular}{|l|l|l|}
\hline Level & Jarak ketinggian bahan bakar dari sensor & Status pompa air \\
\hline$H I G H$ & $2 \mathrm{~cm}$ & $O F F$ \\
\hline$H I G H<L O W$ & $2 \mathrm{~cm} \leq 10 \mathrm{~cm}$ & $O F F$ \\
\hline$L O W$ & $10 \mathrm{~cm}$ & $O N$ \\
\hline
\end{tabular}

Tabel 2 menunjukkan pengujian pengosongan atau penggunaan bahan bakar dari posisi HIGH ke $L O W$, dari tabel tersebut diketahui bahwa pada kondisi full atau level HIGH pompa akan berada pada posisi off sampai bahan bakar mencapai level yang dibutuhkan oleh sistem untuk mengisi Kembali bahan bakar dengan mengaktifkan status pompa menjadi on.

\section{KESIMPULAN}

Berdasarkan hasil penelitian dari perancangan sistem pengisian bahan akar otomatis dapat disimpulkan bahwa sistem berfungsi dengan baik mengisi bahan bakar secara otomatis sesuai dengan pembacaan level yang telah ditentukan, dimana level " $H I G H$ " ketika ketinggian bahan bakar dengan sensor berjarak $2 \mathrm{~cm}$ dan level " $L O W$ " ketika ketinggian bahan bakar dengan sensor berjarak $10 \mathrm{~cm}$. Hasil pembacaan level dari ultrasonic mengontrol pengaktifan relay dan menonaktifkan relay dengan beban sebuah pompa yang ditempatkan di main tank untuk melakukan pengisian bahan bakar secara otomatis ke generator set tank.

\section{DAFTAR PUSTAKA}

[1] Mahmuddin and Nurisra, "Perbandingan Produktivitas Excavator Pada Pekerjaan Pasang/Susun Batu Gunung Ukuran 5-250 Kg Dan 1000-1500 Kg,” J. Tek. Sipil, vol. 1, no. 1, pp. 91-100, 2011.

[2] R. Hermawan, "Praktek Keselamatan Kerja Pada Pengangkutan (Loading) Bahan Bakar Minyak (BBM) Di Instalasi Surabaya Group (ISG), PT. Pertamina (Persero)," Universitas Airlangga, 2012.

[3] A. S. Aviv, A. Wardayanti, E. Budiningsih, A. K. Fimani, and B. Suhardi, "Water Level Control Sistem Otomatis Sederhana pada Tandon Air di Kawasan Perumahan," PERFORMA Media Ilm. Tek. Ind., vol. 15, no. 2, pp. 130-136, 2016.

[4] A. B. Laksono and H. Wahyudi, "Rancang Bangun Water Level Control Pada Embung Daerah Kering Berbasis Mikrokontroller AT-Mega 328," vol. 3, no. 2, p. 42, 2018.

[5] I. Arifin, "Automatic Water Level Control Berbasis Mikrocontroller Dengan Sensor," PendidikanTeknikElektro, pp. 1-56, 2015.

[6] A. Amin, "Jurnal EEICT https://ojs.uniska-bjm.ac.id/index.php/eeict,” J. Ilm. Tek. Elektro, vol. 1, no. 2, pp. 41-52, 2018.

[7] . Azhari, M. I. Jumarang, and A. Muid, "Pembuatan Prototipe Alat Ukur Ketinggian Air Laut Menggunakan Sensor Inframerah Berbasis Mikrokontroler Atmega328," Positron, vol. 4, no. 2, pp. 64-70, 2014.

[8] A. Permana, D. Triyanto, and T. Rismawan, "Rancang Bangun Sistem Monitoring Volume Dan Pengisian Air Menggunakan Sensor Ultrasonik Berbasis Mikrokontroler Avr Atmega8,"

Coding J. Komput. dan Apl. Untan, vol. 03, no. 2, pp. 76-87, 2017.

[9] Irvawansyah and R. A. Azis, "Prototype Sistem Monitoring dan Pengontrolan Level Tangki Air Berbasis SCADA," J. Teknol. Terap. |, vol. 4, no. 1, pp. 27-32, 2018. 